\title{
Analysis of the effect of fines content and loading frequency on the shear modulus and damping ratio of gravels
}

\author{
Análisis del efecto del contenido de finos y la frecuencia de carga en el módulo de corte y \\ razón de amortiguamiento en gravas
}

Fecha de entrega: 20 de agosto 2021

Fecha de aceptación: 10 de noviembre 2021

\section{Leonardo Dorador ${ }^{1}$, Carolina E. Barrera ${ }^{2}$, Jorge Rozas ${ }^{3}$ and Felipe A. Villalobos ${ }^{3}$ \\ ${ }^{1}$ EGSciences SpA, Santiago, Chile, info@egsciences.com \\ ${ }^{2}$ Departamento de Obras Civiles, Universidad Técnica Federico Santa María, Vicuña Mackenna 3939, San Joaquín, Chile, carolina.barrera.13@sansano.usm.cl \\ ${ }^{3}$ Departamento de Ingeniería Civil, Universidad Católica de la Santísima Concepción, Alonso de Ribera 2850, Concepción, Chile, jrozas@ing.ucsc.com, avillalobos@ucsc.cl (Orcid: 0000-0002-5419-3958)}

The dynamic properties of coarse granular soils have been much less studied than in sands. From a database of 14 gravel samples subjected to cyclic triaxial tests, available relationships are studied and new proposed to estimate the normalised shear modulus $G / G_{\max }$ and the damping ratio $D$ as a function of shear strain $\gamma$. The effect of confining stress, fines content, uniformity coefficient and loading frequency on the variation of $G / G_{\max }$ and $D$ versus $\gamma$ is analysed. It is obtained that $G / G_{\text {max }}$ is dependent on confinement, but not on loading frequency. $85.6 \%$ of the data converge in an error band of less than $25 \%$ for the proposed formulation. The damping $D$ does depend on fines content as well as confinement and loading frequency. The proposed formulation for $D$ has a $56 \%$ probability of having errors less than $25 \%$.

Keywords: gravels, shear modulus, damping, loading frecuency, fines content
Las propiedades dinámicas de suelos gruesos han sido mucho menos estudiadas que en arenas. A partir de una base de datos de 14 muestras de gravas sometidas a ensayos triaxiales cíclicos, se estudian relaciones disponibles y se proponen nuevas para estimar el módulo de corte normalizado $G / G_{\max } y$ la razón de amortiguamiento $D$ en función de la deformación de corte $\gamma$. Se analiza el efecto del confinamiento, contenido de finos, coeficiente de uniformidad y frecuencia de carga en la variación de $G / G_{\max } y$ D versus $\gamma$. Se obtiene que $G / G_{\max }$ es dependiente del confinamiento, pero no de la frecuencia de carga. Un $85.6 \%$ de los datos converge en una banda de error menor al $25 \%$ para la formulación propuesta. El amortiguamiento D si depende del confinamiento, asi como del contenido de finos y de la frecuencia de carga. La formulación propuesta para D posee un $56 \%$ de probabilidad de tener errores menores al $25 \%$.

Palabras clave: gravas, módulo de corte, amortiguamiento, frecuencia de carga, contenido de finos

\section{Introduction}

The systematic study of the geomechanical properties of coarse granular materials has historically advanced after that for finer soils such as sands. Special methodologies have had to be developed to analyse coarse granular materials, since laboratory equipment are limited for testing large particles (Ovalle et al., 2020; Dorador and Villalobos, 2020a,b). The study of the dynamic properties of coarse granular material has not been the exception. Since the 1960s several experimental studies have been carried out for the analysis of the dynamic properties of sands to define the shear modulus $G$ and damping ratio $D$ variation with shear strain $\gamma$ (e.g. Hardin, 1965; Hardin and Drnevich, 1972a,b; Ishihara, 1996; Kramer, 1996; Martínez, 2008; Navarrete, 2009, Wichtmann et al., 2015). However, experimental studies with coarse granular 
material started later in the middle of the 1980s when larger samples could be tested in cyclic triaxial apparatus as pointed out by Rollins et al. (1998), who summarise the early works with gravels.

Soil dynamic response can vary significantly depending on the type of cyclic load to which it is subjected which is, for instance, relevant for the design of dams, foundations, walls, coastal and mining structures. The origin of cyclic loads can be diverse, either produced by seismicity (earthquakes), environment (currents, waves, winds) or anthropic (vibratory machines, traffic, trains). The most important parameters for dynamic analysis are the shear modulus $G$ and the damping ratio $D$, both parameters depend strongly on the cyclic shear strain $\gamma$. At low strain levels (less than 10-40), common in vibratory machines, these parameters remain essentially constant. However, for higher cyclic loads, the deformation levels can be considerably higher and the variation of $G$ and $D$ as a function of $\gamma$ should be studied, in order to reduce uncertainty and avoid inappropriate designs.

For gravel samples, Rollins et al. (1998) analysed and selected results of available series of tests from 15 research programmes and based on a one parameter hyperbolic formulation, proposed for sands by Hardin and Drnevich (1972a,b), average curves for the evaluation of $G / G_{\max }-\gamma$ and $D-\gamma$ were developed. Rollins et al. (1998) concluded that $G / G_{\max }-\gamma$ and $D-\gamma$ curves were almost independent on sample disturbance, fines content (range 0-9\%) and gravel content. Additionally, $G / G_{\max }-\gamma$ curves were independent on the relative density. Conversely, $G / G_{\max }-\gamma$ and $D-\gamma$ curves were fairly dependent on the confining stress.

Stokoe et al. (1999) modify the hyperbolic formulation incorporating a second parameter for adjusting the shape of $G-\gamma$ curves. Rollins et al. (2020) adopting this twoparameter hyperbolic formulation re-assess a database of 18 researchers, confirming the dependence on confining stress $\sigma_{\mathfrak{c}}^{\prime}$, and this time also on the grain size distribution in the form of the uniformity coefficient $C_{\mathrm{u}}$. They confirm the independence on relative density and voids ratio, which has also been found by Menq (2003).

From large scale cyclic triaxial testing of rockfill materials, Araei et al. $(2012 \mathrm{a}, \mathrm{b})$ conclude that the loading frequency $f$ can increase the shear modulus at low strain levels, although this effect reduces as strain increases. The $G / G_{\max }-\gamma$ curve decreases with $f$ for a certain value of strain. Damping becomes more affected by $f$ for the whole range of strain level studied. However, these quantitative conclusions were not expressed qualitatively using mathematical relationships.

In this study experimental data available from previous research is analysed in terms of degradation curves of $G / G_{\max }-\gamma$ and $D-\gamma$. The effect of confining stress is included in the analyses together with uniformity coefficient and loading frequency. In addition, the effect of fines content is considered, which has been neglected in previous studies. The formulations proposed for the estimation of the dynamic properties for gravels are statistically assessed to quantify their quality and are compared with previous formulations.

\section{Characteristics of the gravels}

A data set from 6 different research works with 14 samples was compiled, which comprise cyclic triaxial tests in probes of $300 \mathrm{~mm}$ in diameter and 600 and $750 \mathrm{~mm}$ in height. The gravel main characteristics, parameters of the laboratory tests and hyperbolic formulations are summarised in Tables 1 and 2, respectively.

From Table 1 it can be noted that the void ratio $e$ varies between 0.161 and 0.329 , and the uniformity coefficient $C_{\mathrm{u}}$ between 7 and 272. These low values of $e$ are related to the high values of $C_{\mathrm{u}}$, which means that non uniform or well graded grain size distributions give place to much higher packing, hence lower voids. The percentage of gravel-size particles ranges between 55 and $86 \%$, while the percentage of fines does between 0.1 and $14 \%$ and mean diameter $D_{50}$ between 6 and $19 \mathrm{~mm}$ with an average of 11.5 $\mathrm{mm}$, which is above the limit standardized by the Unified Soil Classification System USCS for gravel classification, which corresponds to $4.75 \mathrm{~mm}$ or No. 4 sieve (ASTM D2487, 2017). Therefore, the material is predominantly classified as a gravel - well graded sandy gravel GW. Figure 1 shows the particle size distribution of all the samples indicated in Table 1. 
Table 1: Characteristics of the gravels analysed in the series of tests

\begin{tabular}{|c|c|c|c|c|c|c|c|c|c|}
\hline Reference & Sample & Description & $\begin{array}{c}\text { Gravel, } \\
\%\end{array}$ & $\mathrm{FC}, \%$ & $D_{50}, \mathrm{~mm}$ & $C_{\mathrm{u}}$ & $G_{\mathrm{s}}$ & $\gamma_{\mathrm{d}}, \mathrm{kN} / \mathrm{m}^{3}$ & $e$ \\
\hline \multirow{5}{*}{$\begin{array}{l}\text { Zhou et al. } \\
\text { (2016) }\end{array}$} & HZY-1 & Limestone rockfills & 82.8 & 1.8 & 17.34 & 7.5 & -- & 22.27 & 0.235 \\
\hline & HZY-2 & Limestone rockfills & 74.9 & 2.2 & 14.20 & 30.3 & -- & 22.77 & 0.195 \\
\hline & HZY-3 & Limestone rockfills & 57.8 & 5.9 & 7.85 & 85.3 & -- & 23.25 & 0.205 \\
\hline & HZY-4 & Rhyolite rockfills & 82.8 & 1.8 & 17.34 & 7.5 & -- & 21.58 & 0.235 \\
\hline & LHK-1 & Granite rock grain & 85.8 & 2.4 & 19.17 & 8.8 & -- & 20.31 & 0.241 \\
\hline \multirow{3}{*}{$\begin{array}{l}\text { Araei et al. } \\
\text { (2012a) }\end{array}$} & S.G & $\begin{array}{c}\text { Modeled shell/ } \\
\text { Gotvand }\end{array}$ & 72.6 & 10.0 & 15.71 & 272.1 & 2.59 & 21.50 & -- \\
\hline & S.3AMES & $\begin{array}{c}\text { Dam shell/zone 3A/ } \\
\text { MES }\end{array}$ & 55.0 & 6.5 & 6.45 & 68.8 & 2.64 & 21.20 & 0.281 \\
\hline & S.3BMES & $\begin{array}{c}\text { Dam shell/zone 3B/ } \\
\text { MES }\end{array}$ & 72.0 & 13.8 & 10.78 & -- & 2.64 & 21.80 & 0.280 \\
\hline $\begin{array}{l}\text { Araei et al. } \\
(2012 b)\end{array}$ & S.SBU & $\begin{array}{c}\text { Lime rock (Upper } \\
\text { Siah-Bisheh CFRD) }\end{array}$ & 58.0 & 3.8 & 6.50 & 19.0 & 2.71 & 21.50 & 0.161 \\
\hline \multirow{2}{*}{$\begin{array}{l}\text { Goto et al. } \\
\text { (1992) }\end{array}$} & Depth $5-6 \mathrm{~m}$ & \multirow{2}{*}{$\begin{array}{l}\text { in situ freezing } \\
\text { alluvial gravel }\end{array}$} & 52.3 & 0.1 & 10.00 & 37.5 & -- & 20.68 & -- \\
\hline & Depth $12-13$ m & & 55.0 & 0.5 & 6.00 & 25.0 & -- & 18.91 & -- \\
\hline $\begin{array}{l}\text { Yasuda and } \\
\text { Matsumoto } \\
\text { (1994) }\end{array}$ & Angular & rockfill & 84.1 & -- & 14.82 & 7.0 & 2.65 & -- & -- \\
\hline \multirow{2}{*}{$\begin{array}{l}\text { Hatanaka et al. } \\
\text { (1988) }\end{array}$} & U-4 & in situ freezing & 55.0 & 8.5 & 5.70 & 60.0 & 2.69 & 19.86 & 0.329 \\
\hline & U-5 & deluvial gravel & 65.0 & 0.8 & 10.30 & 13.9 & 2.69 & 20.95 & 0.260 \\
\hline
\end{tabular}

$\%$ gravel: $>4.75 \mathrm{~mm}, \mathrm{FC}$ : fines content, $D_{50}$ : mean grain size, $C_{\mathrm{u}}$ : uniformity coefficient, $G_{\mathrm{s}}$ : specific gravity, $\gamma_{\mathrm{d}}$ : dry unit weight, $e$ : void ratio

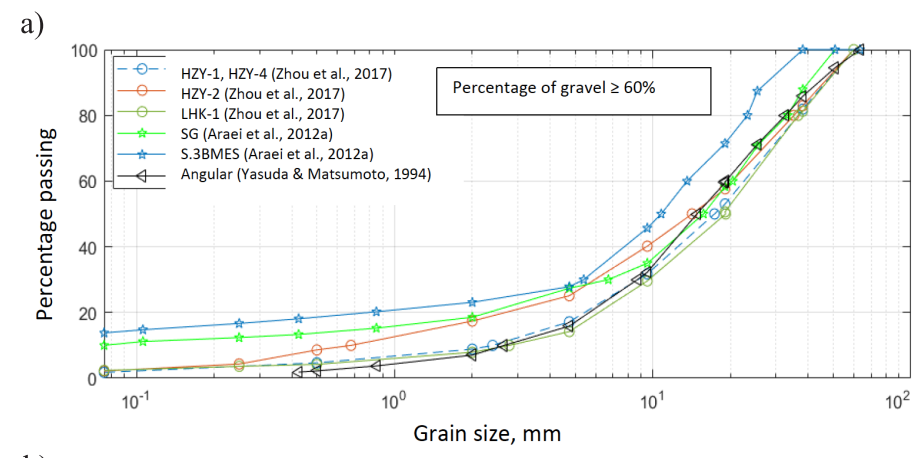

b)

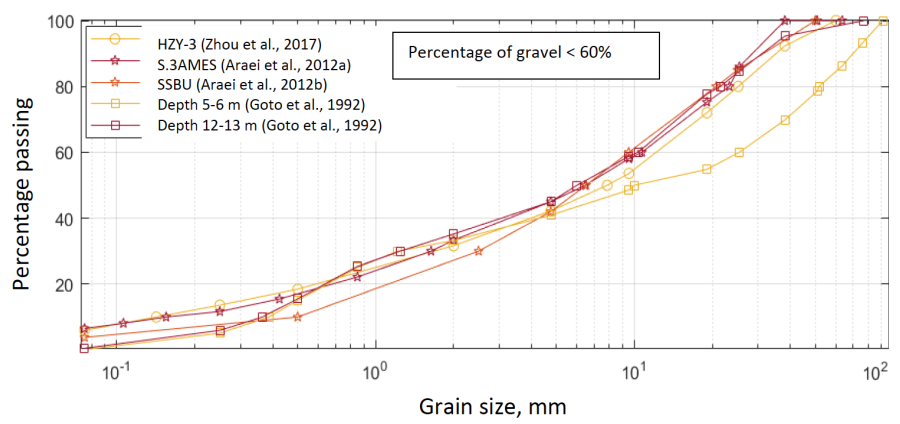

Figure 1: Particle size distribution for: a) more than $60 \%$ of gravel and b) less than $60 \%$ of gravel

\section{$\mathrm{G} / \mathrm{G}_{\max }$ versus shear strain relation}

The representation of the shear modulus $G$ with the cyclic shear strain $\gamma$, is usually dividing $G$ by $G_{\max }$, which is a normalization regularly adopted in practice that allows comparing different results and relationships. Hardin and Drnevich (1972a,b) developed a hyperbolic model widely used in dynamics analysis of sands, which later on was modified by Stokoe et al. (1992) incorporating the curvature parameter $m$. This second parameter can improve the fit of experimental data. The two-parameter hyperbolic model can be expressed as:

$$
\frac{G}{G_{\max }}=\frac{1}{1+\left(\frac{\gamma}{\gamma_{\text {ref }}}\right)^{m}}
$$

where the reference deformation $\gamma_{\text {ref }}$ is used to normalize the shear deformation $\gamma$ such that $G / G_{\max } \approx 0.5$ and $m$ is a curvature parameter. As $m$ increases the shear modulus $G$ increases at small shear strains $\gamma$ and decreases at high levels of $\gamma$. 
Table 2: Cyclic triaxial test and hyperbolic model parameters

\begin{tabular}{|c|c|c|}
\hline Reference & Sample & $\begin{array}{c}d / \mathrm{h}, \\
\mathrm{mm} / \mathrm{mm}\end{array}$ \\
\hline & & \\
\hline & & \\
\hline & $\mathrm{HZY}-1$ & $300 / 750$ \\
\hline & & \\
\hline & & \\
\hline & & \\
\hline & & \\
\hline & $\mathrm{HZY}-2$ & $300 / 750$ \\
\hline & & \\
\hline & & \\
\hline Zhou et al. & & \\
\hline (2017) & & \\
\hline & $\mathrm{HZY}-3$ & $300 / 750$ \\
\hline & & \\
\hline & & \\
\hline & & \\
\hline & HZY -4 & $300 / 750$ \\
\hline & $\mathrm{HZY}-4$ & $300 / 750$ \\
\hline & & \\
\hline & & \\
\hline & LHK-1 & $300 / 750$ \\
\hline & & \\
\hline & & \\
\hline & & \\
\hline & & \\
\hline & & \\
\hline & & \\
\hline & & \\
\hline & & \\
\hline & $S G$ & $300 / 600$ \\
\hline & S.G & $300 / 600$ \\
\hline Araei et al. & & \\
\hline (2012a) & & \\
\hline & & \\
\hline & & \\
\hline & & \\
\hline & & \\
\hline & & \\
\hline & & $300 / 600$ \\
\hline & S.3AMES & $300 / 600$ \\
\hline & $5.3 B M E S$ & $300 / 600$ \\
\hline & S.3BMES & $300 / 600$ \\
\hline & & \\
\hline & & \\
\hline & & \\
\hline & & \\
\hline & & \\
\hline & & \\
\hline & & \\
\hline & & \\
\hline & & \\
\hline & & \\
\hline & & \\
\hline & & \\
\hline & & \\
\hline & & \\
\hline & & \\
\hline & & \\
\hline & & \\
\hline & & \\
\hline & & \\
\hline & & \\
\hline Araei et al. & SSBU & $300 / 600$ \\
\hline (2012b) & $5.5 B U$ & $300 / 600$ \\
\hline & & \\
\hline & & \\
\hline & & \\
\hline & & \\
\hline & & \\
\hline & & \\
\hline & & \\
\hline & & \\
\hline & & \\
\hline & & \\
\hline & & \\
\hline & & \\
\hline & & \\
\hline & & \\
\hline & & \\
\hline & & \\
\hline & & \\
\hline & & \\
\hline & & \\
\hline & & \\
\hline & Depth 5-6 & \\
\hline Goto et al. & & $300 / 600$ \\
\hline (1992) & \begin{tabular}{|l|} 
Depth 12-13 \\
\end{tabular} & $300 / 600$ \\
\hline & $\mathrm{m}$ & \\
\hline & & \\
\hline Matsumoto & Angular & $300 / 600$ \\
\hline (1994) & & \\
\hline & $1 H-4$ & \\
\hline Hatanaka et & $0-4$ & $300 / 600$ \\
\hline al. (1988) & U-5 & $300 / 600$ \\
\hline & U-5 & \\
\hline
\end{tabular}

$d$, $h$ : sample diameter and height, SU: saturated undrained, DD: dry drained, $\sigma_{1}^{\prime}, \sigma_{3}^{\prime}$ : major and minor effective stress, $\gamma_{\text {ref }}$ : reference shear strain, $m$ : exponent 
According to Ishihara (1996), the reference deformation $\gamma_{\text {ref }}$ reflects the transition from linear elastic to non-elastic behaviour. When the soil behaves elastically, strains are concentrated in the contact between particles, with little or no rotation, while non-linear behaviour occurs when the relative movement between grains begins. The nonlinearity is a function of the fines content, since for a soil subjected to cyclic loading with a high fines content, it would tend to initiate a lower reference deformation and lose its stability due to interlocking, causing a greater reduction in shear modulus $G$. However, in coarse soils, the loss of stability by interlocking requires a greater mobilizing strain, causing a lower reduction in $G$ (Rollins et al., 2020).

For this reason, it is necessary to quantify $\gamma_{\text {ref }}$ as accurate as possible. In this context, there are different formulations to determine the value of $\gamma_{\text {ref }}$ and $m$. Such is the case by Stokoe et al. (1999), who proposed an average value of $m=0.87$ for sands, resulting relatively independent of the void ratio and confining stress. For gravels, Rollins et al. (1998) suggested average values of $m=0.84$ and $\gamma_{\text {ref }}=0.04$.

Based on the analysis performed by Stokoe et al. (1999) and data by Rollins et al. (1998), Rollins et al. (2020) propose for gravels an expression for $\gamma_{\text {ref }}$ as a function of the confining stress, defined as:

$$
\gamma_{\mathrm{ref}}=a\left(\sigma_{\mathrm{c}}^{\prime}\right)^{b}
$$

where $\sigma_{\mathrm{c}}^{\prime}$ is the confining stress in $\mathrm{kPa}, a=0.0039$ and $b=$ 0.42 . Since these values of $a$ and $b$ are relatively close to those proposed for sands ( $a=0.0063, b=0.38$ (Darandeli, 2001; Rollins et al., 2020)), although $\gamma_{\text {ref }}$ is higher in sands than in gravels for the same value of $\sigma_{\mathrm{c}}^{\prime}$, this difference is generally considered negligible (Kokusho et al., 2005; Rollins et al., 2020). So, combining (1) and (2) results:

$$
\frac{G}{G_{\max }}=\frac{1}{1+\left(\frac{\gamma}{0.0039\left(\sigma_{\mathrm{c}}^{\prime}\right)^{0.42}}\right)^{0.84}}
$$

Then, expression (3) can provide for gravels curves of $G / G_{\max }$ as a function of the shear strain $\gamma$ and the confining stress $\sigma_{\mathrm{c}}^{\prime}$, which tend to be more linear as $\sigma_{\mathrm{c}}^{\prime}$ increases and below the curves for sands (Darandeli, 2001). Additionally, Menq (2003) proposes an expression for $\gamma_{\text {ref }}$ versus $\sigma_{c}^{\prime}$ which includes the influence of the uniformity coefficient $C_{\mathrm{u}}$. Following this idea of including $C_{\mathrm{u}}$, Rollins et al. (2020) derived another expression for $\gamma_{\text {ref }}=f\left(\sigma_{\mathrm{c}}^{\prime}, C_{\mathrm{u}}\right)$ based on statistical analyses of a much larger database.

$$
\frac{G}{G_{\max }}=\frac{1}{1+\left(\frac{\gamma}{0.0046\left(C_{u}\right)^{-0.197}\left(\sigma_{\mathrm{c}}^{\prime}\right)^{0.52}}\right)^{0.84}}
$$

In expression (4), the gravel stiffness increases with $\sigma_{c}^{\prime}$ reducing the stiffness degradation. Conversely, when $C_{\mathrm{u}}$ increases, the curves of $G / G_{\max }-\gamma$ move downwards and to the left because of the lower value of $\gamma_{\text {ref }}$.

\section{Frequency and fines content effects}

The dominant frequency in seismic events has been found to be below $15 \mathrm{~Hz}$ (Araei et al., 2012a,b), although it may range between $0.01 \mathrm{~Hz}$ and $30 \mathrm{~Hz}$ (Meng, 2007). For that reason, a loading frequency range between $0.01 \mathrm{~Hz}$ and $10 \mathrm{~Hz}$ has been usually adopted in experimental studies as shown in Table 2. Taken the data from Table 2 and plotting $G / G_{\max }$ as a function of $\gamma$ and $\gamma_{\text {ref }}$, where $\gamma_{\text {ref }}$ is expressed as a function of $\sigma_{c}^{\prime}$ and the loading frequency $f$, results:

$$
\begin{aligned}
\gamma_{\text {ref }} & =\frac{0.0033\left(\sigma_{\mathrm{c}}^{\prime}\right)^{0.305}}{f^{0.242}} \\
\frac{G}{G_{\max }} & =\frac{1}{1+\left(\frac{\gamma f^{0.242}}{0.0033\left(\sigma_{\mathrm{c}}^{\prime}\right)^{0.305}}\right)^{0.858}}
\end{aligned}
$$

In Figure 2, measured and estimated 946 values of $G / G_{\max }$ are compared, where the statistical analysis indicates that when using (6) approximately $85.6 \%$ of the data fall within the $\pm 25 \%$ error band, while only $2.2 \%$ is outside $\pm 50 \%$. Whereas, measured and estimated 922 values of $G / G_{\max }$ using (4) results in $60.5 \%$ of the data falling within $\pm 25 \%$, and $16.8 \%$ are outside $\pm 50 \%$ of error. Therefore, the use of (5) and (6) can lead to an enhancement in the prediction of $G / G_{\max }$. Moreover, it can be observed that data from expression (6) is distributed symmetrically around the $1: 1$ centre line, which is in contrast with the data from expression (4) leaning on the left side of the plot resulting in many outlier points. 


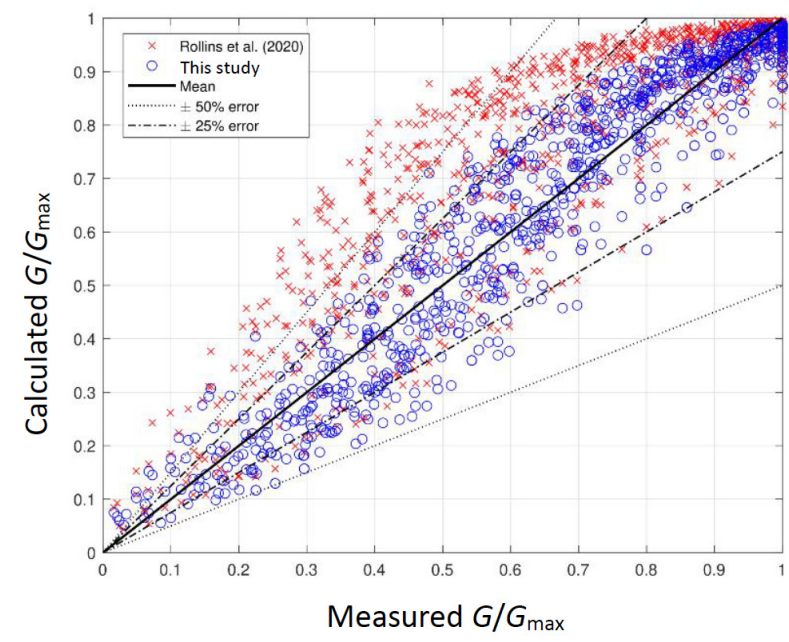

Figure 2: Comparison between measured and estimated $G / G_{\max }$ using Rollins et al. (2020) formulation (4) and this study proposal using expressions (5) and (6)

Figure 3 shows the error in estimating $G / G_{\max }$. It can be observed that for $G / G_{\max }=0.5$, i.e. $\gamma_{\text {ref, }}$ the error is concentrated under $50 \%$ for the data calculated using expression (6), whereas the points calculated with expression (4) can reach approximately $75 \%$ error. For values close to $85 \%$ of $G / G_{\max }$, the error decreases almost similarly for both formulations.

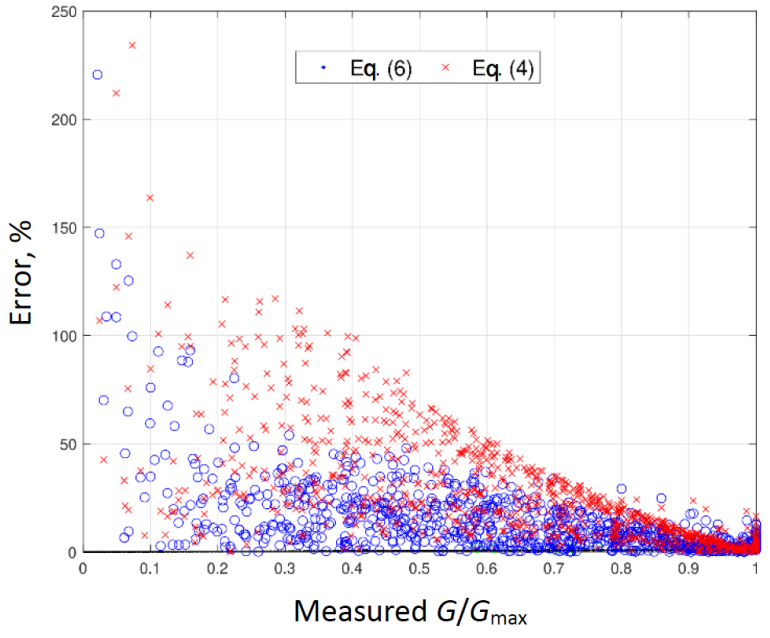

Figure 3: Error in estimating $G / G_{\max }$ comparing Rollins et al. (2020) formulation (4) and this study proposal (6)

Figure 4 shows the data points from the cyclic triaxial tests presented in Table 2. It is clear to see the scatter in the progressive degradation of stiffness with the shear strain between $0.1 \%$ and $0.001 \%$. Due to this scatter, the need arises to be able to recalibrate a single characteristic curve whose purpose is to improve the representation of the $G / G_{\max }$ variation. In this context, the mean variation

a)

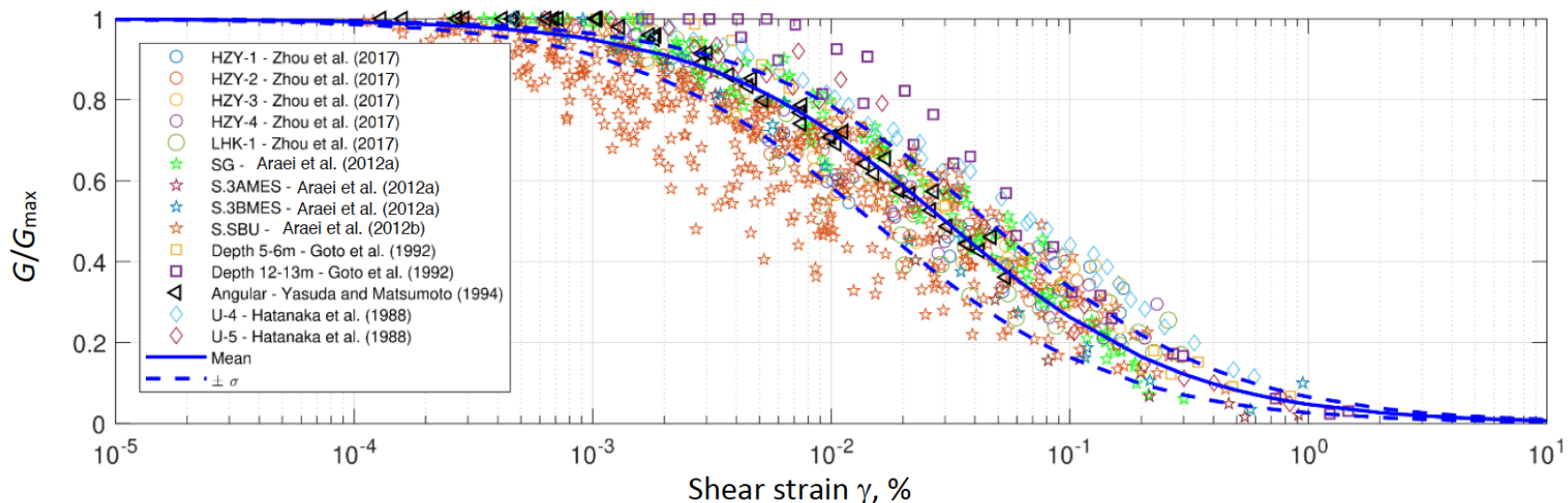

b)

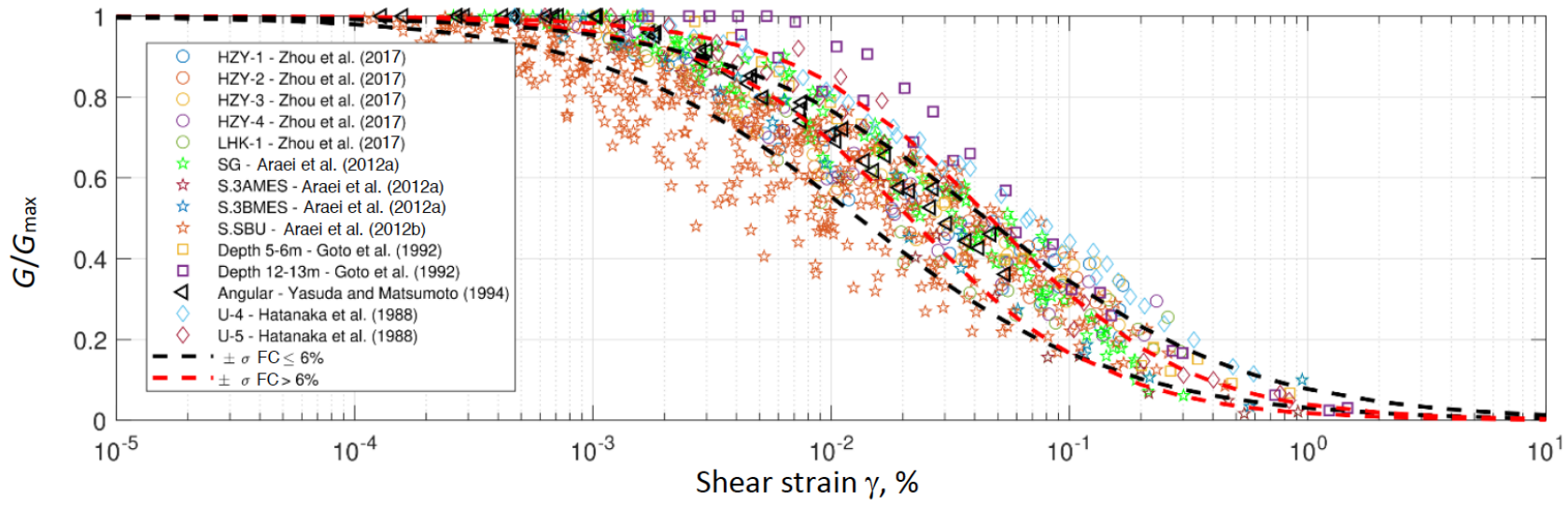

Figure 4: Variation of $G / G_{\max }$ versus $\gamma$ including measured data points (Tabla 2) and curves of best fit with a) limits of \pm one standard deviation $\sigma$ and b) limits of $\pm \sigma$ for the classification by fines content FC 
(continuous line) with its respective \pm standard deviation $\mathrm{Sd}$ (segmented lines) is plotted using expression (1). Therefore, according to the statistical analysis, the average values are; $\gamma_{\text {ref }}=0.030 \pm S d_{\gamma}=0.015$ and $m=0.858 \pm S d_{\mathrm{m}}$ $=0.212$.

In order to be able to better differentiate the gravel dynamic response in terms of shear stiffness, the data was divided in two groups according to the sample fines content FC. This division was established at $\mathrm{FC}=6 \%$, as shown in Figures $4 \mathrm{~b}, 5 \mathrm{a}$ and $5 \mathrm{~b}$. For a level of shear stress of less than $0.1 \%$, the best fitted curves to the data with $\mathrm{FC}>6 \%$ are slightly to the right side and with steeper slope, i.e. higher stiffness variation than for the data with $\mathrm{FC} \leq 6 \%$. However, for shear strains greater than $0.1 \%$, the opposite tends to occur. The best fit of the data corresponds to the regression analysis that combines both groups, since the errors in the estimation individually were slightly greater than the data set treated as only one group. From the regression analyses, the parameter values that best fit the data for FC $\leq 6 \%$ are: $\gamma_{\text {ref }}=0.029 \pm S d_{\text {rref }}=0.016$ and $m$ $=0.797 \pm S d_{m}=0.179$, whilst for FC $>6 \%: \gamma_{r e f}=0.034 \pm$ $S d_{\gamma r e f}=0.013$ and $m=1.047 \pm S d_{m}=0.190$.

a)

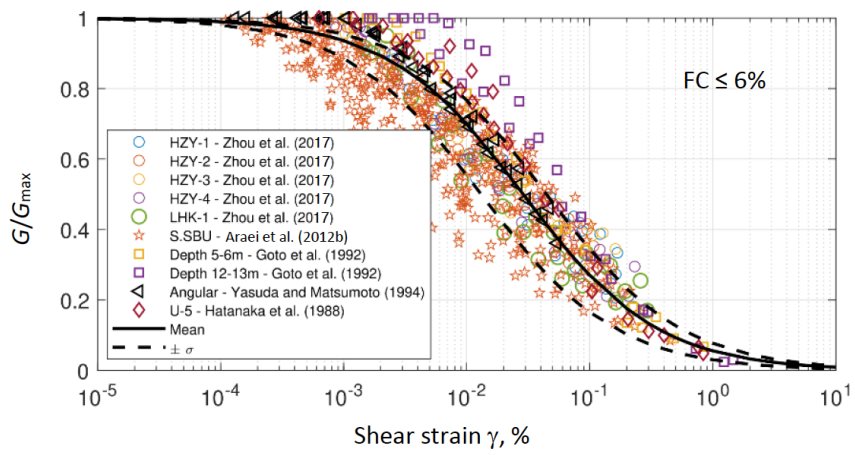

a)

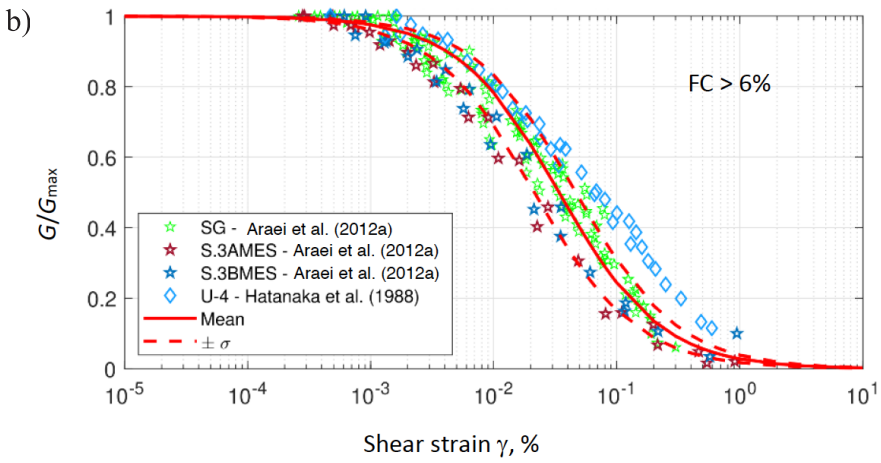

Figure 5: Data division respect to the fines content FC: a) $\leq 6 \%$ and b) $>6 \%$
Figure 6 shows a three dimensional plot with the database from Table 2 including the formulation proposed in (5) and (6) in terms of $G / G_{\max }$ as a function of $\gamma$ and $f$. It can be observed that most of the data is for low values of loading frequency and the stiffness degradation pattern tends to be similar for the entire frequency range analysed. Therefore, loading frequency does not really influence significantly the shear modulus $G$ at least for the frequency range considered in these analyses. This is not in agreement with Araei et al. (2012a), who conclude for their data that the increase in loading frequency $f$ does increase $G$, but at low strain, because as strain increases the $G$ increase rate reduces with the increase of $f$. Moreover, Araei et al. (2012a) also conclude that $G / G_{\max }-\gamma$ decreases when $f$ increases for a certain value of strain. More data is then needed for higher values of frequency $(f>10 \mathrm{~Hz})$ to validate the applicability of the proposed formulation.

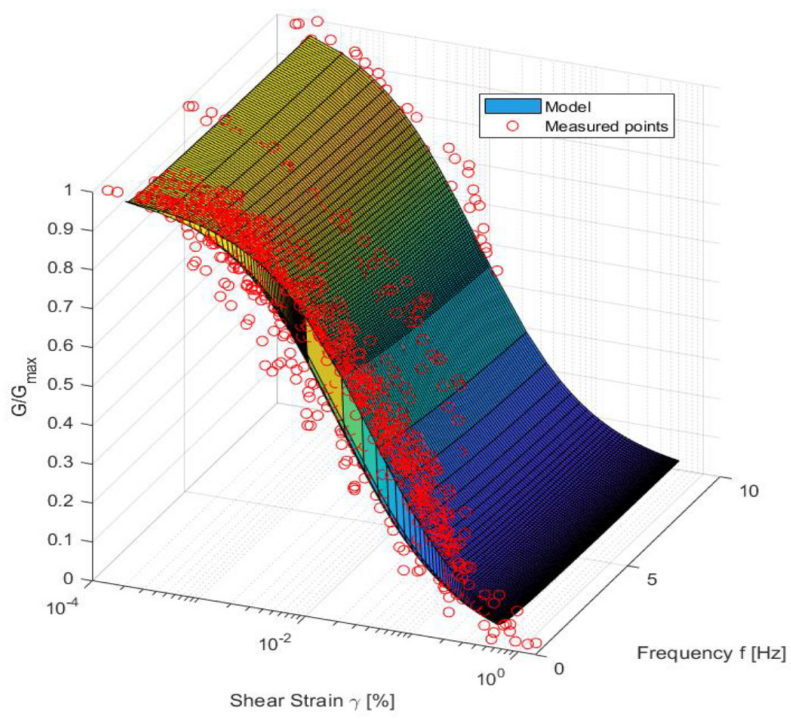

Figure 6: 3D plot for $G / G_{\max }=f(\gamma, f)$ data and formulation proposed

\section{Damping ratio $D$}

Damping is a definition for the dissipation of stored energy during cyclic loading. Damping ratio $D$ is the normalisation of the dissipated energy by the stored elastic strain energy. For sands, it has been known that $D$ is small and constant for very low levels of cyclic shear strains $\gamma\left(<10^{-4} \%\right)$, however, it can increase steadily with higher values of $\gamma$ (e.g. Hardin, 1965; Hardin and Drnevich, 1972a,b; Martínez, 2008; Navarrete, 2009). Therefore, under strong cyclic loading $D$ can vary and the use of only one 
low or medium $D$ value is an oversimplification that may not always allow adequate dynamic analyses. The study of $D$ for gravels started in the middle of the 1980s and a summary of available results has been reported by Rollins et al. $(1998,2020)$. From the database available, Rollins et al. (1998) proposed the following best fit hyperbolic expression for $D$ :

$$
D=0.8+18\left(1+0.15 \gamma^{-0.9}\right)^{-0.75}
$$

where $D$ and $\gamma$ are in percentage. It has been found that the use of (7) generally can over or underestimate $D$ in around $25 \%$ for $D>10 \%$, whereas for $D<10 \%$, the variation of $D$ can be of $50 \%$ or even more. Another approach was followed by Stokoe et al. (1999) when they proposed that $D$ could be estimated by means of $G / G_{\max }$ using a modified version of the Masing rule and the number of cycles. However, it has been argued that the Masing approach overestimates $D$ in particular at high strain levels (e.g. Hardin and Drnevich, 1972a; Vucetic and Dobry, 1991). Moreover, the Masing rule approach results in $D=0$ in the small strain range (Darandeli, 2001). Despite these observations, Rollins et al. (2020) present a modified Masing formulation considering $D_{\min }=1 \%$, typical value from the database analysed. Confining stress $\sigma_{c}^{\prime}$ and uniformity coefficient $C_{\mathrm{u}}$ are implicitly introduced through $G / G_{\max }$ formulations, resulting in $D-\gamma$ curves bounded by (7) with $D \pm 30 \%$, showing that $D$ tends to decrease with $\sigma_{\mathrm{c}}^{\prime}$ and increase with $C_{\mathrm{u}}$. This confirms that damping has an opposite behaviour compared to the shear modulus. However, the Masing approach leads to similar over and underestimations as those obtained by (7).

In order to obtain an explicit relationship for $D=f\left(\sigma_{\mathrm{c}}^{\prime}, C_{\mathrm{u}}\right)$, i.e. without $G / G_{\max }$, Rollins et al. (2020) developed the following expression from a regression analysis.

$D=26.05\left(\frac{\gamma}{1+\gamma}\right)^{0.375} C_{u}^{0.08} \sigma_{\mathrm{c}}^{\prime-0.07}$

Nevertheless, in statistical terms (8) is neither significantly better than (7) nor the Masing approach (Rollins et al., 2020).

\section{Frequency and fines content effects}

In the same form as it was included in the stiffness analyses, frequency and fines content FC may affect the dynamic response of gravels. Taken the data from Table 2 and carrying out a best fit analysis, results in the following expressions:

$$
\begin{aligned}
& D= \begin{cases}m\left(\frac{\gamma}{1+\gamma}\right)^{0.306}, & \text { FC } \leq 6 \% \\
m\left(\frac{\gamma}{1+\gamma}\right)^{0.236}, & \text { FC }>6 \%\end{cases} \\
& m=11.343 f-10.008 \log \left(\sigma_{\mathrm{c}}^{\prime}\right)+45.331
\end{aligned}
$$

Figure 7 shows the plot with measured points and proposed curves by Rollins et al. (1998) and using (10). The scatter points away from the main trend represent the frequency effect (Araei et al., 2012b). The proposed formulation aims to include the frequency effect in the estimation of $D$.

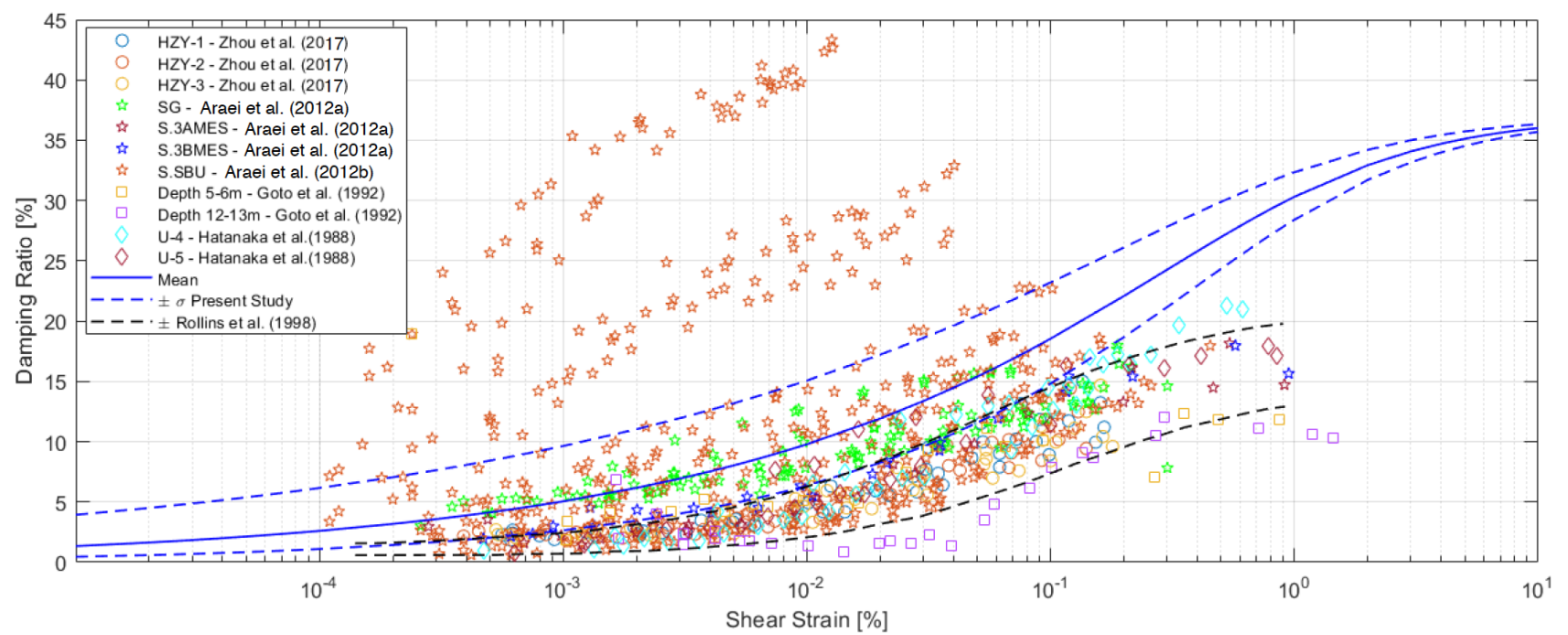

Figure 7: D- $\gamma$ data and curves proposed by Rollins et al. (1998) and this study showing mean and standard deviation 
Figure 8 shows the error between measured and estimated values of $D$, where for expression (7) by Rollins et al. (1998) and expression (8) by Rollins et al. (2020) the error is around $30 \%$ with the data points falling within the bands of $25 \%$ error from the 1:1 line of perfect measuredestimated agreement. By comparison, using (9) and (10) results in $56 \%$ of the data falling in the $25 \%$ error.

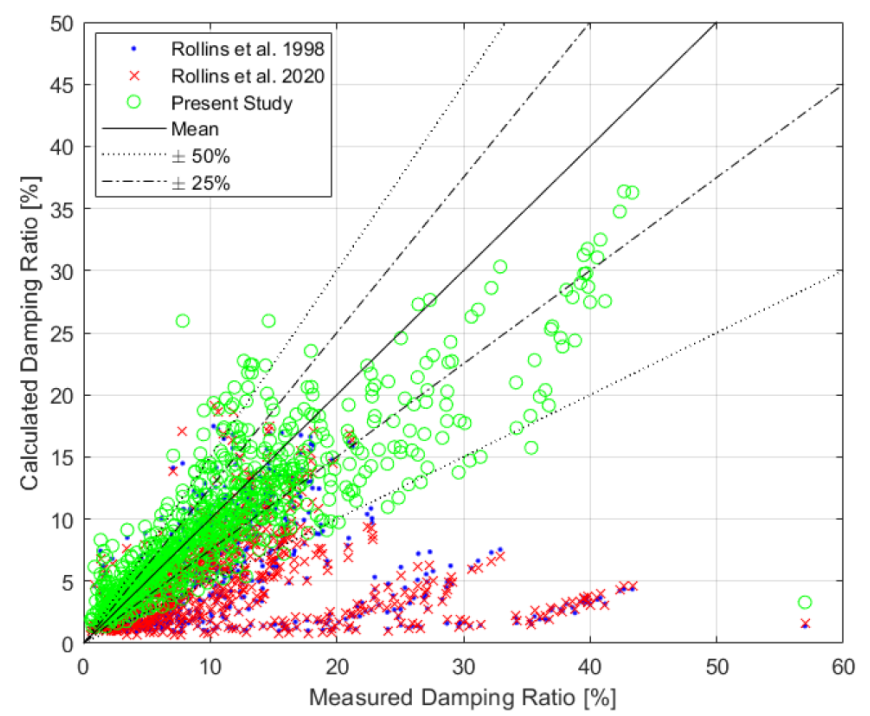

Figure 8: Comparison of $D$ measured data with estimations from formulations by Rollins et al. $(1998,2020)$ and proposed in this study

The mean curve and standard deviation for (9) and (10) are strongly influenced by the data from Araei et al. (2012b), which is not included in the database of Rollins et al. $(1998,2020)$ and for that reason this curve is above the curve proposed by Rollins et al. (1998), as also shown in Figure 7.

Figure 9a shows results of $D-\gamma$ for the fines content FC $\leq 6 \%$ where it can be observed significant scatter in the data and the curves from (9) and (10) predict higher $D$ than those by Rollins et al. (1998). In Figure 9b for FC $>6 \%$, there is less data and scatter and the same higher $D$ is also predicted, although with some overlapping.

At higher levels of non-plastic fine material, it has been consistently reported in sands lower levels of damping ratio $D$ and higher levels of shear modulus $G$ (Navarrete, 2009; Wichtmann et al., 2015). In gravels, Figure 10 shows similar trend for $D$ in a 3D plot of $D-\gamma-f$ where the curve from expression (9) for $\mathrm{FC}<6 \%$ lies above the curve for $\mathrm{FC} \geq 6 \%$. Although, for low shear strain $\gamma$ and low frequency $f$, both curves tend to converge underestimating measured $D$, when $\gamma$ and $f$ increase both curves steadily separate increasing $D$.
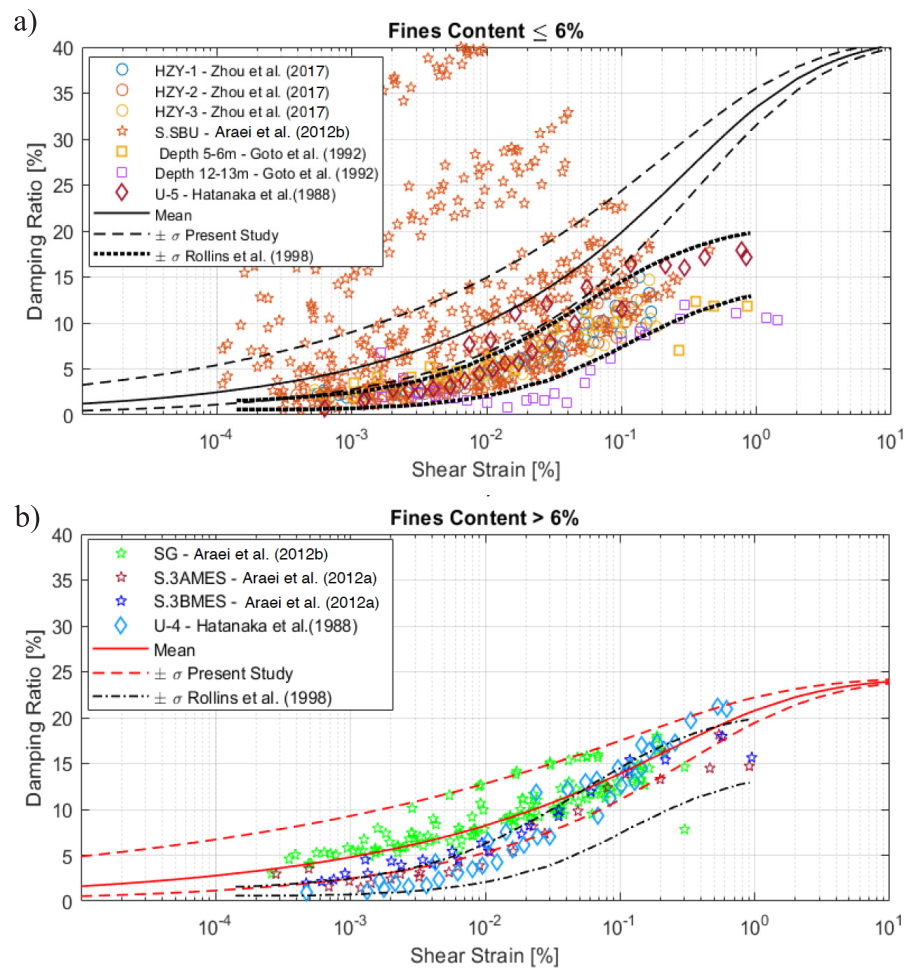

Figure 9: $D-\gamma$ data and curves proposed by Rollins et al. (1998) and this study showing mean and standard deviation for: a) FC $\leq 6 \%$ and b) $\mathrm{FC}>6 \%$

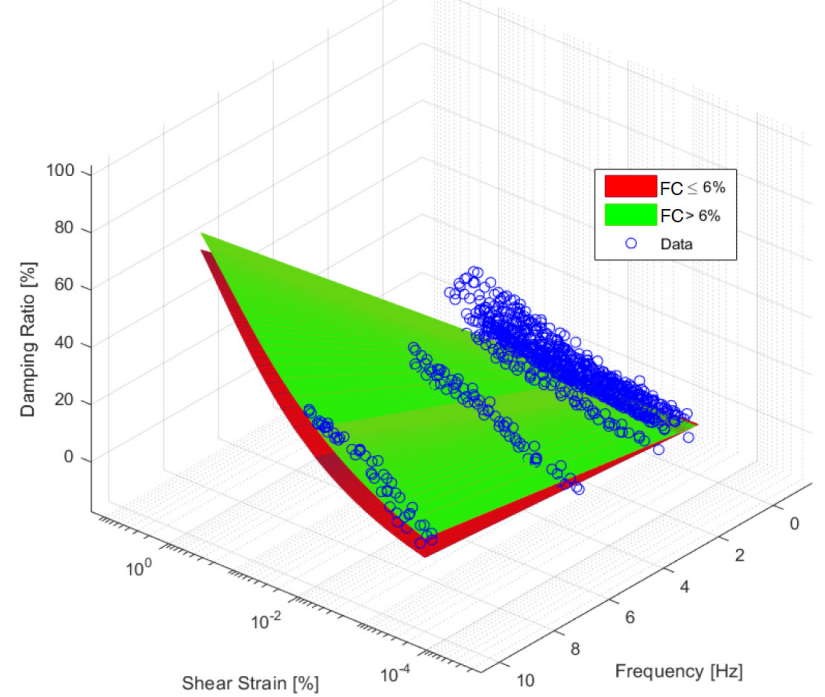

Figure 10: 3D plot for the data and formulations proposed for damping ratio $D$ as a function of $\gamma, f$ and $\mathrm{FC}$ 


\section{Conclusions}

This study presents the analysis of a selected database of cyclic triaxial tests in gravely soils applying hyperbolic formulations for the variation of shear modulus and damping ratio as a function of shear strain. It has been confirmed that the confining stress affects the dynamic response of gravels as it has been previously reported (Rollins at al., 2020). It has been found in this work that including the confining stress and the fines content a better estimation of $G / G_{\max }$ can be achieved, resulting in $85.6 \%$ of the data (in measured and estimated $G / G_{\max }$ plot) within an error band of $\pm 25 \%$, which improve around $25 \%$ the previous formulation proposed by Rollins et al. (2020). In a plot of error versus estimated $G / G_{\max }$, the error increases when $G / G_{\max } \rightarrow 0$, i.e. large shear strains, however, the formulation proposed in this work can reduce this error up to $50 \%$ compared with that proposed by Rollins et al. (2020). Nonetheless, the error reduces and becomes similar for both approaches when $G / G_{\max } \geq 0.8$ (small shear strains). The effect of the loading frequency is not significant on the estimation of $G / G_{\max }$, which does not agree with some effect on the shear modulus found by Araei et al. (2012b). In contrast, the loading frequency does affect the damping ratio $D$ as postulated by Araei et al. (2012b). From regression analyses and separating at $6 \%$ fines content, in a measured and estimated data plot of $D$ resulted in $56 \%$ of the data points within a $\pm 25 \%$ band error. Further research is needed to increase the gravel data base for the analysis of extended ranges of loading frequency and fines content.

\section{References}

Araei, A.A., Tabatabaei, S.H. and Razeghi, H.R. (2012a). Cyclic and post-cyclic monotonic behavior of crushed conglomerate rockfill material under dry and saturated conditions. Scientia Iranica 19(1), 64-76

Araei,A.A., Razeghi, H.R., Tabatabaei, S.H. and Ghalandarzadeh, A. (2012b). Loading frequency effect on stiffness, damping and cyclic strength of modeled rockfill materials. Soil Dynamics and Earthquake Engineering 33(1): 1-18

ASTM D2487 (2017). Standard practice for classification of soils for engineering purposes (Unified Soil Classification System). West Conshohocken, PA, USA
Darendeli, M.B. (2001). Development of a new family of normalized modulus reduction and material damping curves. University of Texas at Austin, USA

Dorador, L. and Villalobos, F.A. (2020a). Scalping techniques in geomechanical characterization of coarse granular materials. Obras y Proyectos 28, 24-34

Dorador, L. and Villalobos, F.A. (2020b). Analysis of the geomechanical characterization of coarse granular materials using the parallel gradation method. Obras y Proyectos 27, 50-63 Goto, S., Suzuki, Y., Nishio, S. and Oh-Oka, H. (1992). Mechanical properties of undisturbed Tone River gravel obtained by in-situ freezing method. Soils \& Foundations 32(3), 15-25

Hardin, B.O. and Drnevich, V.P. (1972a). Shear modulus and damping in soils: design equations and curves. Journal of the Soil Mechanics and Foundation Division 98(7), 667-692

Hardin, B.O. and Drnevich, V.P. (1972b). Shear modulus and damping in soils: measurement and parameter effects (Terzaghi lecture). Journal of the Soil Mechanics and Foundation Division 98(6):603-624

Hardin, B.O. (1965). The nature of damping in sands. Journal of the Soil Mechanics and Foundation Division 91(1), 63-67

Hatanaka, M., Suzuki, Y., Kawasaki, T. and Endo, M. (1988). Cyclic undrained shear properties of high quality undisturbed Tokyo Gravel. Soils \& Foundations 28(4), 57-68

Ishihara, K. (1996). Soil behaviour in earthquake geotechnics. Oxford University Press, UK

Kokusho, T., Aoyagi, T. and Wakunami, A. (2005). In-situ soil specific nonlinear properties back-calculated from vertical array records during 1995 Kobe Earthquake. Journal of Geotechnical and Geoenvironmental Engineering 131(12): 1509-1521

Kramer, S.L. (1996). Geotechnical earthquake engineering. Pearson, USA

Martínez, R.A. (2008). Influencia de la granulometría en las propiedades dinámicas de suelos no cohesivos bajo pequeñas deformaciones. Obras y Proyectos 3, 22-31

Meng, J. (2007). Earthquake ground motion simulation with frequency-dependent soil properties. Soil Dynamics and Earthquake Engineering 27: 234-241

Menq, F.Y. (2003). Dynamic properties of sandy and gravelly soils. PhD thesis, University of Texas at Austin, USA 
Navarrete, M. (2009). Influencia del contenido de finos no plástico en la rigidez y el amortiguamiento a bajas amplitudes de deformación en arenas cuarzosas. Obras y Proyectos 6, 19-30

Ovalle, C., Linero, S., Dano, C., Bard, E., Hicher, P. Y. and Osses, R. (2020). Data compilation from large drained compression triaxial tests on coarse crushable rockfill materials. Journal of Geotechnical and Geoenvironmental Engineering 146(9), 06020013

Rollins, K.M., Singh, M. and Roy, J. (2020). Simplified equations for shear-modulus degradation and damping of gravels. Journal of Geotechnical and Geoenvironmental Engineering 146(9):04020076.

Rollins, K.M., Evans, M.D., Diehl, N.B., and Daily, W.D. (1998). Shear modulus and damping relationships for gravels. Journal of Geotechnical and Geoenvironmental Engineering 124(5): 396-405

Stokoe, K.H., Darendeli, M.B., Andrus, R.D and Brown, L.T. (1999). Dynamic soil properties: laboratory, field and correlation studies. $2^{\text {nd }}$ International Conference on Earthquake Geotechnical Engineering, Lisboa, Portugal, Seco e Pinto, P.S. (ed.), Balkema, the Netherlands, 811-845
Vucetic, M. and Dobry, R. (1991). Effect of soil plasticity on cyclic response. Journal of Geotechnical Engineering 117(1): 89-107

Wichtmann, T., Navarrete, M.A. and Triantafyllidis, T. (2015). On the influence of a non-cohesive fines content on small strain stiffness, modulus degradation and damping of quartz sand. Soil Dynamics and Earthquake Engineering 69, 103-114

Yasuda, N. and Matsumoto, N. (1994). Comparisons of deformation characteristics of rockfill materials using monotonic and cyclic loading laboratory tests and in-situ tests. Canadian Geotechnical Journal 31(2), 162-174

Zhou, W., Chen, Y., Ma, G., Yang, L. and Chang, X. (2017). A modified dynamic shear modulus model for rockfill materials under a wide range of shear strain amplitudes. Soil Dynamics and Earthquake Engineering 92, 229-238 